\title{
A Rare Case of Concomitant Intramedullary Gangliocytoma at the Cervicomedullary Junction in Patient with Neuroendocrine Tumor of Lung
}

\author{
Fatih Aydemir, M.D., ${ }^{1}$ Melih Cekinmez, M.D., ${ }^{1}$ Ozgur Kardes, M.D., ${ }^{1}$ Fazilet Kayaselcuk, M.D. ${ }^{2}$ \\ Departments of Neurosurgery, ${ }^{1}$ Pathology, ${ }^{2}$ Baskent University Faculty of Medicine, Adana, Turkey
}

\begin{abstract}
Ganglion cell tumors (GCT) are divided into two subtypes : gangliocytoma and ganglioglioma. Intramedullary gangliocytomas are extremely rare. A 20-year-old male patient with pain of neck, who also had a previously known neuroendocrine tumor of lung, was operated for mass found in the cervicomedullary junction with a presumptive diagnosis of metastases. Only partial resection could be performed. Pathological diagnosis had been reported as gangliocytoma. Only ten cases of intramedullary gangliocytoma have been reported in the literature. Although association with scoliosis and Von Recklinghausen's disease were previously reported in the literature, no gangliocytoma case concomitant with endocrine tumor of lung have been published. Pathological study is the most important diagnostic method for gangliocytomas. Surgical excision is the primary treatment, but difficulty in total surgical tumor resection is the most important problem.
\end{abstract}

Key Words : Gangliocytoma · Intramedullary · Tumor.

\section{INTRODUCTION}

Ganglion cell tumors (GCT) are divided into two sub-types : gangliocytoma and ganglioglioma. Although intramedullary gangliocytoma are extremely rare, intramedullary gangliogliomas are more frequent. Only ten cases of intramedullary gangliocytoma have been reported in the literature. Only one gangliocytoma case located at cervicomedullary junction has been published ${ }^{15)}$. Although association with scoliosis and Von Recklinghausen's disease were previously reported in the literature, no gangliocytoma cases concomitant with neuroendocrine tumor of lung have been published. In this report, we aim to present a gangliocytoma case at cervicomedullary junction in a patient with neuroendocrine tumor of lung and discuss diagnosis and treatment options with literature.

\section{CASE REPORT}

A 20-year-old male patient admitted with pain of neck and head. The patient underwent 2 surgeries previously 6 and 3 year ago due to neuroendocrine tumor of lung and had received octreotide therapy. Cervical magnetic resonance (MR) imaging revealed a $45 \times 14 \mathrm{~mm}$ sized mass lesion mixed with cystic and solid components, calcification foci extending from medulla oblongata to $\mathrm{C} 2$ level, with edema or infiltration areas extending to C6 level, and the mass was heterogeneous on T1-weighted MR imaging, hyperintense on T2-weighted MR imaging and solid components showed intense contrast-enhancing following injection of Gadolinium (Gd) (Fig. 1). Metastasis was considered in the first place in preliminary diagnosis. The patient was scheduled for surgery. Suboccipital craniectomy and C1 laminectomy were performed following brainstem mapping with neurophysiological monitoring. The dura was opened in the midline. Cervicomedullary junction was found to be enlarged. After midline myelotomy, a stiff-structured gray tumor with unclear boundaries was encountered. Partial resection was performed with the help of ultrasonic aspirator (Fig. 2). Operation was terminated upon detection of increase in temporary somatosensory evoked potential latencies and decrease in motor evoked potential amplitudes during the operation. Postoperative neurological examination was intact. On microscopic examination, intense inflammation, lots of ganglion cells with focal calcification that stained positively with $\mathrm{S} 100$ and synaptophysin. No obvious glial component was detected with glial fibrillary

- Received : October 21, 2015 • Revised : December 5, 2015 •Accepted : February 10, 2015

- Address for reprints : Fatih Aydemir, M.D.

Department of Neurosurgery, Baskent University Faculty of Medicine, Dadaloglu Street No. : 6, Adana 01250, Turkey

Tel : +90-322-3272727, Fax : +90-322-3271273, E-mail : md.fatihaydemir@gmail.com

- This is an Open Access article distributed under the terms of the Creative Commons Attribution Non-Commercial License (http://creativecommons.org/licenses/by-nc/3.0) which permits unrestricted non-commercial use, distribution, and reproduction in any medium, provided the original work is properly cited. 

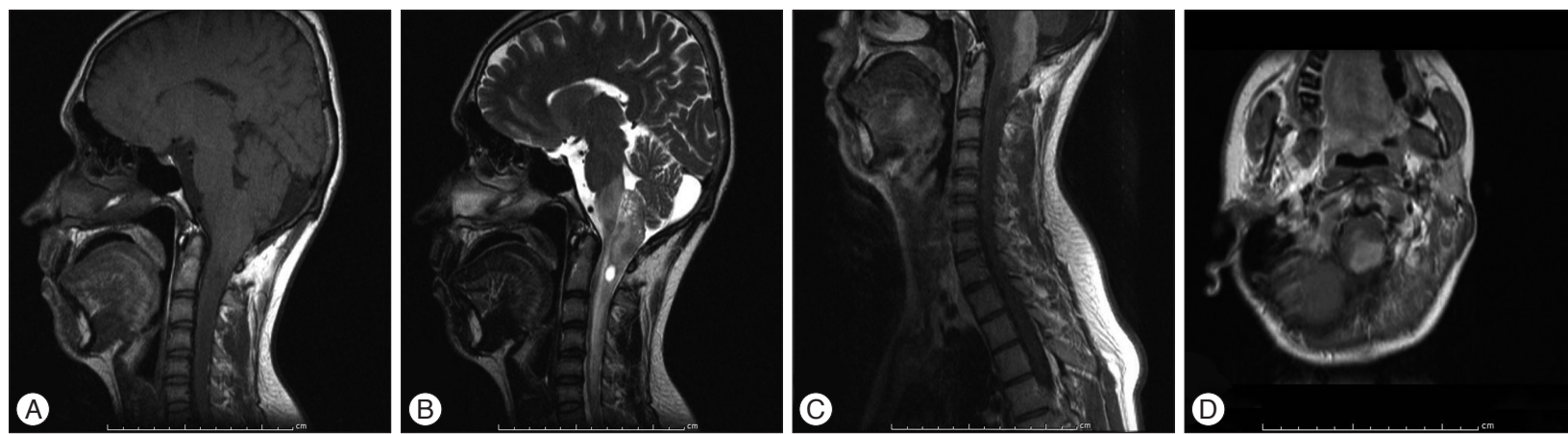

Fig. 1. Diffuse cord edema extending from medulla oblongata to $C 6$ level and cystic component are seen on sagittal $T 1$ (A) and T2 (B) weighted MR images. Intense contrast-enhancing lesion approximately $44 \times 14 \mathrm{~mm}$ in size extending from medulla oblongata to C2 level on post-contrast sagittal $\mathrm{T} 1$ (C) and axial T1 (D) weighted MR images.
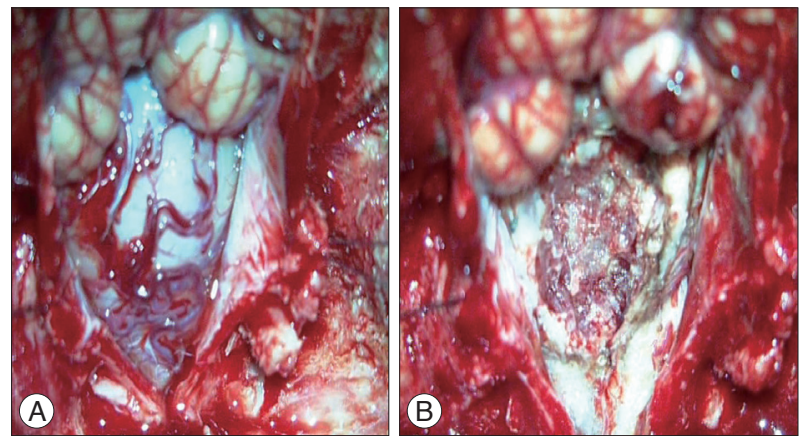

Fig. 2. Expansion of the cord is observed at cervicomedullary junction following dural opening (A), tumor cavity is seen after partial resection (B).

acidic protein (GFAP). Ki67 was 1\%. In the light of these findings, the case was reported as grade 1 gangliocytoma pathology (Fig. 3). No adjuvant therapy was given. The patient had no neurologic deficits at 3-month follow-up and radiographic progression was not detected.

\section{DISCUSSION}

Ganglioglioma accounts for $0.4-7.6 \%$ of pediatric central nervous system (CNS) neoplasms and $1.3 \%$ of those in adults ${ }^{8)}$. They are slowly growing benign tumors and malignant transformation may be seen in less than $10 \%{ }^{16}$. Generally, they are located in the supratentorial region and most commonly involve temporal lobe. Brain stem and spinal location are rare. Spinal location has been reported to be associated with scoliosis. Gangliocytoma are $0.1 \%$ to $0.5 \%$ of all CNS tumors and children and young adults constitute $60 \%$ of all patients ${ }^{5}$. Intracranial location is usually seen in temporal lobe, frontoparietal region and floor of 3rd ventricle, gangliocytoma involving cerebellum is described as Lhermitte-Duclos disease ${ }^{5}$. Association with scoliosis and Von Recklinghausen's disease was reported ${ }^{5)}$. Intramedullary spinal cord and cervicomedullary junction gangliocytomas are extremely rare. Up to date, nine cases for spinal cord and only one case cervicomedullary junction gangliocytomas were reported in the literature $\mathrm{e}^{1-7,11,13,15)}$.

Clinical symptoms usually vary depending on spinal cord compression or infiltration of located region. They may present
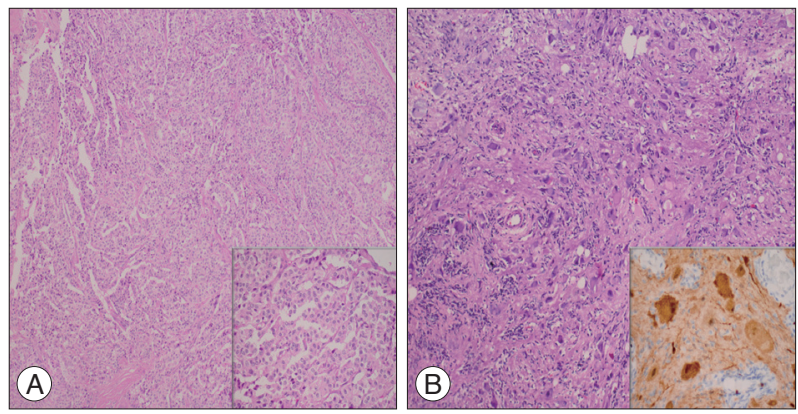

Fig. 3. Neuroendocrine tumor of lung $H \& E \times 100$, inlet : closer view of tumor cells H\&E $\times 400(A)$, neoplastic development in ganglion cells H\&E $\times 100$, inlet : $S-100$ positive staining ganglion cells, original magnification $\mathrm{H} \& \mathrm{E} \times 400$ (B).

with neurological symptoms ranging from pain, as in our case, radiculopathy, paraparesis and paraplegia. Although there are no significant radiological imaging features, they are usually hypointense on T1-weighted MR imaging and hyperintense on T2-weighted MR imaging and are enhancing lesions at different rates $^{15}$. Astrocytoma, brain stem gliomas, ependymomas and metastases should be considered in differential diagnosis.

Ganglioglioma consist of dysplastic neurons and neoplastic glial cells, whereas gangliocytoma have dysplastic neural cells and normal glial cells ${ }^{2,22}$. Immunohistochemical study aids the confirmation of diagnosis of ganglion cell tumor. The glial populations are reactive for GFAP, S-100 protein, and vimentin, but the neurons are for synaptophysin and Chromogranin $\mathrm{A}^{9,10,14)}$.

Primary treatment of GCT is surgical excision and they are considered resistant to other adjuvant therapies, as they are well-differentiated slow-growing tumors. However, malignant transformations have been reported in the literature ${ }^{5)}$. Radiological follow-up is done for patients who underwent total excision, but adjuvant therapy remains controversial in patients who underwent subtotal excision. Total resection is difficult in reported cervical-junction GCTs. As published in the literature, only four of 10 cases of intramedullary gangliocytoma underwent gross total resection ${ }^{6,7,13,15)}$. Gangliocytoma cases published in the literature do not have enough follow-up periods. Jacob et $\mathrm{al}^{5)}$. reported no clinical and radiographic progression in a partially resected case in 3-year follow-up. 
In our case, because of pre-existing neuroendocrine tumor of lung, metastases were considered in the first line and operation has been decided although there were no neurological deficits. Although association with scoliosis and Von Recklinghausen's disease were previously reported in the literature, no GCT cases concomitant with neuroendocrine tumor of lung have been published.

With increasingly reported GCTs in recent years, they should be kept in mind in the differential diagnosis of intramedullary tumors especially in children and young adults. Pathological study is the most important diagnostic method for GCTs. Surgical excision is the primary treatment, but difficulty in total surgical tumor resection is the most important problem.

\section{References}

1. Azzarelli B, Luerssen TG, Wolfe TM : Intramedullary secretory gangliocytoma. Acta Neuropathol 82 : 402-407, 1991

2. Baehring J, Ogle E, Sze G, Duncan C, Bannykh S : Ganglioneurocytoma of the spinal cord. J Neurooncol $71:$ 149, 2005

3. Choi YH, Kim IO, Cheon JE, Kim WS, Yeon KM, Wang KC, et al : Gangliocytoma of the spinal cord : a case report. Pediatr Radiol 31 : 377380, 2001

4. Coca S, Moreno M, Martos JA, Rodriguez J, Barcena A, Vaquero J : Neurocytoma of spinal cord. Acta Neuropathol 87 : 537-540, 1994

5. Jacob JT, Cohen-Gadol AA, Scheithauer BW, Krauss WE : Intramedullary spinal cord gangliocytoma : case report and a review of the literature. Neurosurg Rev 28 : 326-329, 2005
6. Kalyanaraman UP, Henderson JP : Intramedullary ganglioneuroma of spinal cord : a clinicopathologic study. Hum Pathol 13 : 952-955, 1982

7. Komotar RJ, O’Toole JE, Mocco J, Khandji AG, Keller CE, Connolly ES Jr, et al. : Gangliocytoma of the spinal cord. Neurosurgery 60 : 895-900; discussion 895-900, 2007

8. Kwon JW, Kim IO, Cheon JE, Kim WS, Chi JG, Wang KC, et al. : Cerebellopontine angle ganglioglioma : MR findings. AJNR Am J Neuroradiol 22 : 1377-1379, 2001

9. Lagares A, Gómez PA, Lobato RD, Ricoy JR, Ramos A, de la Lama A : Ganglioglioma of the brainstem : report of three cases and review of the literature. Surg Neurol 56 : 315-322; discussion 322-324, 2001

10. Milligan BD, Giannini C, Link MJ : Ganglioglioma in the cerebellopontine angle in a child. Case report and review of the literature. J Neurosurg 107 (4 Suppl) : 292-296, 2007

11. Ng TH, Fung CF, Goh W, Wong VC : Ganglioneuroma of the spinal cord. Surg Neurol 35 : 147-151, 1991

12. Rosenblum MK : Central nervous system, Rosai J (eds) : Rosai and Ackerman's Surgical Pathology, ed 9. Edinburgh : Mosby, 2004, pp24612622

13. Russo CP, Katz DS, Corona RJ Jr, Winfield JA : Gangliocytoma of the cervicothoracic spinal cord. AJNR Am J Neuroradiol 16 (4 Suppl) : 889-891, 1995

14. Shin JJ, Oh SH, Yoon DH, Kim TS : Cervical ganglioglioma. J Korean Neurosurg Soc 30 : 239-243, 2001

15. Wakao N, Imagama S : Intramedullary gangliocytoma with calcification and multiple intramedullary cysts. Neuroradiology $54:$ :893-895, 2012

16. Yang C, Li G, Fang J, Wu L, Yang T, Deng X, et al. : Intramedullary gangliogliomas : clinical features, surgical outcomes, and neuropathic scoliosis. J Neurooncol 116 : 135-143, 2014 